\title{
The Biological Effects of Venom Derived from the Ectoparasitic Wasp Eulophus pennicornis (Nees) (Hymenoptera: Eulophidae): Evidence for Dual Endocrine Regulation
}

\author{
Howard A. Bell ${ }^{*}, 1$, Michelle E. Powell ${ }^{1}$, Dan R.G. Price ${ }^{2}$ and Robert J. Weaver ${ }^{1}$ \\ ${ }^{I}$ The Food and Environment Research Agency, Sand Hutton, York YO41 1LZ, UK \\ ${ }^{2}$ Biological and Biomedical Sciences, University of Durham, South Road, Durham, DH1 3LE, UK
}

\begin{abstract}
The venom of the ectoparasitoid Eulophus pennicornis is known to induce developmental arrest in parasitized hosts through the prevention of moulting. However, little work has explored how the venom affects different host stages, whether the observed effects vary with different doses, and whether the venom has activity in non-host species.

Injections of venom doses of $\geq 0.5 \mu \mathrm{g}$ protein prevented the development of $>90 \%$ of both fifth and sixth instar Lacanobia oleracea larvae. In fifth instars, developmental arrest at doses of $\geq 1.0 \mu \mathrm{g}$ occurred prior to ecdysis to the sixth stadium, whilst the 0.5 and $0.25 \mu \mathrm{g}$ treatments allowed $36 \%$ and $77 \%$ of injected larvae, respectively, to moult although most subsequently failed to pupate. Although naturally parasitized hosts always showed reduced growth, lower doses of venom often prevented pupation without affecting this parameter, particularly in sixth instar larvae where only the highest dose (2.0 $\mu \mathrm{g}$ ) reduced the mean maximum weights achieved. Two factitious lepidopteran hosts, Manduca sexta and Spodoptera littoralis, were also affected by injection of the venom at w/w doses equivalent to those used for L. oleracea although larvallarval moulting was only prevented in the former.

Fractionation of venom using gel-filtration FPLC indicated the presence of at least two factors that markedly affected host development. One series of contiguous fractions, on injection, prevented larval-larval ecdysis in a similar way to whole venom. A second series of fractions had no effect on larval-larval ecdysis but resulted in the formation of deformed pupae, an effect that closely resembled the application of a juvenile hormone $(\mathrm{JH})$ analogue, which may indicate the presence of a factor within the venom that modulates host levels of this hormone.
\end{abstract}

Keywords: Lacanobia oleracea, Noctuidae, juvenile hormone, ecdysteroids, parasitoid-host interactions.

\section{INTRODUCTION}

Parasitic wasps frequently alter their host's physiology following parasitism through a process known as host regulation [1]. These manipulations are mediated by factors introduced into hosts by the female wasp, such as venom and polydnavirus, larval secretions, or teratocytes derived from the serosal membrane of the parasitoid's egg [1-3]. These factors modify the physiology and immunology of the host in several ways in order to create a resource that is favourable for the development of the wasp's progeny. Such maternally-derived compounds play a crucial role in the reproductive success of many parasitoids and successful development of a parasitoid's offspring frequently cannot proceed in their absence.

Recently, it has been reported that the gregarious ectoparasitoid Eulophus pennicornis (Nees) manipulates juvenile hormone $(\mathrm{JH})$ levels in larvae of its host, the tomato moth Lacanobia oleracea (L.) [4]. This manipulation leads to a ca. 100-fold increase in JH levels in sixth instars within five days of parasitism. Similar manipulations of host JH levels have been widely reported for a range of parasitoid

*Address correspondence to this author at the The Food and Environment Research Agency, Sand Hutton, York YO41 1LZ, UK; Tel: +44 (0)1904 462 669; Fax: +44 (0)1904 462 111; E-Mail: howard.bell@fera.gsi.gov.uk species [5-7] and up-regulation of this hormone appears to a very common aspect of parasitoid-induced host regulation. Increases in host $\mathrm{JH}$ levels are thought, amongst other things, to prevent the well characterized physiological changes associated with pupal commitment that would occur when insects are parasitized close the end of their larval development, especially during the final larval stadium $[4,8,9]$.

Previous investigations using E. pennicornis have reported that ecdysteroid titres are markedly altered following parasitism by this parasitoid [10,11], with the magnitude of the manipulation being highly dependent on the larval stadium of the host at the point of parasitism. Manipulation of ecdysteroid titres manifests itself in both parasitized and artificially envenomated hosts as a significant reduction and delay in the increase in 20-hydroxyecdysone (20E) levels that would normally occur prior to ecdysis in non-parasitized hosts [12]. This effect of the wasp's venom was initially thought to be closely allied to the elimination of ecdysis that parasitized or venom-injected caterpillars always exhibit although recent work has indicated that $20 \mathrm{E}$ manipulation alone cannot explain the elimination of moulting [8]. A similar situation occurs in the ectoparasitoid Euplectrus plathypenae Howard where there is evidence that arrestment factors directly affect the epidermal tissue without the need for interaction with other areas of the body [13]. However, it has been shown in a related species, Euplectrus comstockii 
Howard, that different arrestant mechanisms may be operating in different host instars, with $20 \mathrm{E}$ levels being significantly affected in Trichoplusia ni (Hübner) larvae in the final stadium but not in the preceding larval stage. Such a variable strategy to deal with hosts within different stadia has been similarly indicated for E. pennicornis [4].

Whilst the existing body of work on E. pennicornis has shed light on some of the physiological manipulations elicited by this wasp, there has been little exploration of whether the elimination of moulting and upregulation of $\mathrm{JH}$ are mediated by a single venom factor or from the combined activity of several different components. Furthermore, the observable effects of venom factors on various aspects of host development have not been reported in any detail, particularly with respect to injection into different host stages, and the response of larvae to different doses. These points are of particular relevance as E. pennicornis has the ability to parasitize a range of stages of $L$. oleracea (fourth, fifth and sixth stadium larvae) and to vary its clutch precisely in proportion to the size of the host [14]. Furthermore, the reproductive success of this parasitoid appears linked to both its ability to identify the highest quality hosts and to successfully regulate their development $[8,14]$. These observations are best illustrated by the fact that late-parasitized hosts (i.e. those within 3-4 days of pupation) continue to develop following parasitism, and form prepupae, a developmental event that leads to very poor parasitoid larval survival; whereas larvae parasitized at the start of the final stadium prove to be optimal and are preferentially parasitized by this wasp [14].

The developmental arrest that always occurs in hosts following parasitization by E. pennicornis, or artificial envenomation [15], may mean that other, potentially observable, venom-induced effects are masked. In the present study, experiments were designed to investigate the effect of a range of venom doses on the host, so that the full potential spectrum of host responses might be observed. The developmental effects of the venom were also explored in two factitious hosts that E. pennicornis does not parasitize. Following this, through partial separation of the factors present in the wasp's venom, it was also investigated as to whether different types of activity (i.e. distinct effects on the host) could be observed in L. oleracea larvae that mirror the various effects induced through injection of varying doses of whole venom. In order to equate some of the observed developmental outcomes with $\mathrm{JH}$ manipulation, the effects of some venom fractions were compared with the morphogenetic disruption caused by the exogenous application to host larvae of the $\mathrm{JH}$ analogue methoprene.

\section{MATERIALS AND METHODS}

\section{Insects}

Newly emerged E. pennicornis adults were derived from a laboratory culture maintained on late stadium larvae of the tomato moth, L. oleracea, at $25^{\circ} \mathrm{C}, 70 \%$ R.H. and $16 \mathrm{~h}: 8 \mathrm{~h}$ L:D according to the methods described previously [16]. Lacanobia oleracea larvae were derived from a laboratory culture maintained at $20^{\circ} \mathrm{C}$ and $16 \mathrm{~h}: 8 \mathrm{~h} \mathrm{~L}: \mathrm{D}$ and reared on artificial diet [17] in plastic sandwich boxes (150x150x75 $\mathrm{mm}$ ) covered with muslin lids. Procedures for rearing, staging, and synchronising larvae have been described previ- ously [18]. Experiments utilized larvae in the fifth and sixth stadia only. All experiments were carried out at $25^{\circ} \mathrm{C}, 70 \%$ R.H. and 16h:8h L:D.

Larvae of the cotton leafworm, Spodoptera littoralis (Boisduval), were derived from a laboratory culture and reared following essentially the same procedures as described for $L$. oleracea. Larvae of the tobacco hornworm, Manduca sexta (L.), were reared from eggs kindly supplied by Prof. Stuart Reynolds (University of Bath) and reared as previously described [19].

\section{Preparation of E. pennicornis Venom}

Mixed age female wasps (approx. 1-2 weeks old) were removed from culture and chilled at $4{ }^{\circ} \mathrm{C}$ for approximately $30 \mathrm{~min}$. The wasps were then immersed in a vial of phosphate buffered saline dissection buffer (PBS, $25 \mathrm{mM}$ $\mathrm{NaH}_{2} \mathrm{PO}_{4}, 25 \mathrm{mM} \mathrm{NaHPO}, 155 \mathrm{mM} \mathrm{NaCl}, 7 \%$ sucrose) and held over ice for a further 10 minutes. Wasps were subsequently transferred to the stage of a dissecting microscope and placed in a small volume (ca. $50 \mu \mathrm{l})$ of chilled dissection buffer. The venom sacs of the wasps were removed through gently pulling on the ovipositor with a pair of fine forceps to reveal the sac. The removed sacs were then placed in a 1.5 $\mathrm{ml}$ microcentrifuge tube held over ice until approximately 50-100 sacs had been collected. The venom sacs were gently macerated and debris removed through centrifugation at $10,000 \mathrm{~g}, 4^{\circ} \mathrm{C}$, for $10 \mathrm{~min}$. The venom preparations were stored at $-20^{\circ} \mathrm{C}$ until use.

\section{Activity of Crude Venom}

The anti-moulting activity of crude venom was investigated against $L$. oleracea larvae. The protein content of venom preparations was determined using the method of Bradford [20] using BSA as a standard. Dilutions of the venom were prepared to produce doses that would deliver $0.05 \mu \mathrm{g}$ to $2 \mu \mathrm{g}$ protein content when injected into hosts in 5 $\mu l$ of dissection buffer.

Newly moulted fifth or sixth instar L. oleracea larvae (< $12 \mathrm{~h}$ after ecdysis) were removed from culture and chilled over ice. Subsequently, the insects were anaesthetized with $\mathrm{CO}_{2}$ and injected with $5 \mu \mathrm{l}$ of a crude venom dilution using a $10 \mu \mathrm{l}$ Hamilton syringe. The larvae were place individually in $250 \mathrm{ml}$ plastic pots, provided with artificial diet ad libitum and monitored until death or pupation. Developmental events such as moulting, the occurrence of supernumerary stadia, and pupal deformity were recorded and 10-33 larvae were injected for each instar and dose. A sample of injected fifth instar L. oleracea $(\mathrm{n}=10-15$ for each dose $)$ and all $(\mathrm{n}=10$ 20) sixth instar larvae were also weighed daily. As well as the usual laboratory host of E. pennicornis, injections were also performed using two factitious hosts. In the case of $S$. littoralis, insects were selected from laboratory culture as newly ecdysed fifth instar larvae, injected as described above using the $0.5 \mu \mathrm{g}$ dose, and growth and development monitored until death or pupation. Larvae of M. Sexta were raised individually up to the start of the fourth stadium, injected with $5 \mu \mathrm{g}$ of venom protein (in $10 \mu \mathrm{l}$ of dissection buffer) and subsequently maintained at $20^{\circ} \mathrm{C}, 60 \%$ R.H, $16: 8$ LL:DD. Controls for both species were injected with equivalent volumes of buffer only. 


\section{Fractionation of E. pennicornis Venom}

Venom samples were subjected to separation using a fast pressure liquid chromatography (FPLC) system fitted with a Superose-12 HR 10/30 gel filtration column coupled to a Beckman 168 diode array detector. After equilibrating the column with Dulbecco's PBS (Sigma), fractionation was initiated by injecting $\sim 1000 \mu \mathrm{g}$ of venom protein (ca. 300 venom sacs) in $0.2 \mathrm{ml}$ of dissection buffer onto the column. Proteins were eluted with buffer at a flow rate of $0.4 \mathrm{ml} / \mathrm{min}$. The UV detector was set at $280 \mathrm{~nm}$ and monitored at 0.4 AUFS sensitivity using Beckman 32 Karat software. Fractions $(0.4 \mathrm{ml})$ were collected over a period of $75 \mathrm{~min}$ at 1 min intervals. The bed volume of the column was $24 \mathrm{ml}$ and the void volume $7.6 \mathrm{ml}$. Bio-Rad protein standards for gel filtration were used for column calibration.

Venom fractions from several gel filtrations were pooled in batches of three consecutive fractions. Subsequently, these pooled fractions were concentrated by ultrafiltration using Millipore Ultra-free-MC centrifugal concentrators $(5,000$ NMWL) spun at $5000 \mathrm{~g} 4^{\circ} \mathrm{C}$ until volumes had been reduced by $50-60 \%$ (typically $1-2$ hours). These pooled fractions were bioassayed for activity (see below) and, on the basis of the results obtained, individual $1 \mathrm{~min}$ fractions were collected from further FPC separations using the procedures described above, concentrated and subjected to further investigation.

\section{Biological Activity of $E$. pennicornis Venom Fractions}

The biological activity of FPLC fractions was examined through bioassay against fifth instar L. oleracea, as described above for whole venom. Ten $L$. oleracea were injected with $5 \mu \mathrm{l}$ of pooled sample of three contiguous fractions. The injected insects were kept individually and monitored until death or pupation. Control insects received $5 \mu \mathrm{l}$ of Dulbecco's PBS only. A total of 24 pooled fractions were assayed (eluting between 10 to 72 minutes) and any developmental abnormalities were noted.

Where the injection of pooled samples revealed observable activity, further injections using the individual $1 \mathrm{~min}$ fractions spanning these areas were undertaken. The protein content of each individual fraction was determined prior to injection (as described above). In addition to noting developmental abnormalities, the effect of selected fractions on the growth of L. oleracea was also measured. In these cases, larvae injected at the start of the fifth stadium were weighed daily until pupation or death.

The activity of some fractions appeared to have activity of a type similar to the exogenous application of juvenile hormone to lepidopteran larvae. In order to explore this observation further, a number of newly emerged fifth and sixth stadium $L$. oleracea were topically treated with the juvenile hormone analogue (JHA) (S)-methoprene. Solutions of 50 $\mu \mathrm{g} \mu \mathrm{l}^{-1}$ and $100 \mu \mathrm{g} \mu \mathrm{l}^{-1}$ of the JHA were prepared in acetone and cohorts of 15-20 insects, within $12 \mathrm{~h}$ of moulting to the fifth or sixth stadium, were treated with $1.0 \mu \mathrm{l}$ of one of the two concentrations. Control insects were treated with $1.0 \mu 1$ of acetone only. Subsequently, all insects were monitored for developmental normality, as described above. A proportion of the insects were weighed daily to allow comparisons to be made with larvae injected with venom or venom fractions.
Totals of 10-20 insects of each instar were treated with each methoprene dose.

\section{Statistical Analysis}

Statistical analysis was conducted using StatsDirect 2.6.1. The calculation of $\mathrm{LD}_{50}$ values for crude venom was achieved using Probit analysis. Effects on host weights and developmental times were analyzed using one-way analysis of variance (ANOVA) and, where appropriate, means separated by Dunnet multiple range post-hoc tests for the comparison of treated insects with the controls. Unpaired Student's t-tests were used for the comparison of two means. In all cases the accepted level of significance was $\mathrm{P}<0.05$.

\section{RESULTS}

\section{Activity of Crude Venom}

The effect of crude venom preparations on the normal development of fifth and sixth instar L. oleracea is shown in Fig. (1). Venom doses of $0.1 \mu \mathrm{g}$ and above had a marked effect on the successful development of larvae injected at the start of the sixth stadium. As a result, only $25 \%$ of those insects injected with $0.1 \mu \mathrm{g}$ of venom protein $\left(0.6 \mu \mathrm{g} \mathrm{g}^{-1}\right)$ at the start of the final larval stadium developed normally and formed viable pupae whilst doses of $1.0 \mu \mathrm{g}$ and above eliminated all normal development. Fifth instar larvae were less affected by the $0.1 \mu \mathrm{g}$ venom dose $\left(1.6 \mu \mathrm{g} \mathrm{g}^{-1}\right.$ fresh weight) than sixth instar caterpillars, with over $60 \%$ developing normally whilst the effect of higher doses was essentially the same as that of the final stadium larvae. When the doseresponses for both larval stages were examined, approximate $\mathrm{LD}_{50}$ values of $2.8 \mu \mathrm{g} \mathrm{g}^{-1}$ and $0.58 \mu \mathrm{g} \mathrm{g}^{-1}$ were calculated for fifth and sixth instar larvae, respectively.

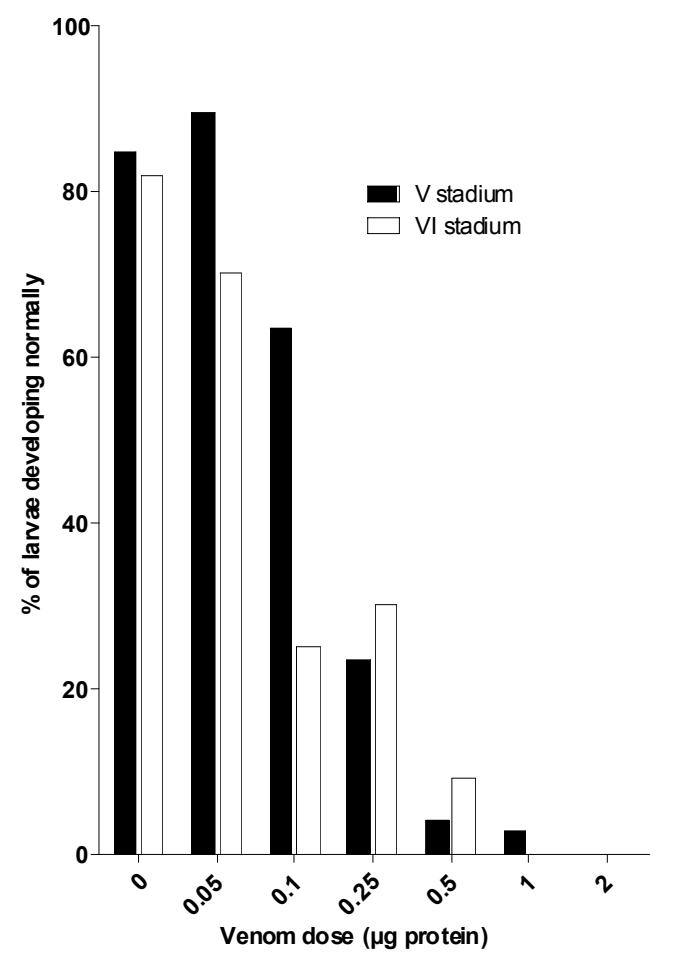

Fig. (1). The proportion of venom injected fifth and sixth stadium L. oleracea larvae that developed normally to form viable pupae following injection with E. pennicornis venom at the stated dose. 
Table 1. The Effect on the Successful Development of L. oleracea Larvae Following Injection with Doses of Crude Venom at the Start of Either the Fifth or Sixth Stadium

\begin{tabular}{|c|c|c|c|c|c|c|c|c|}
\hline $\begin{array}{c}\text { Venom Dose }(\mu \mathrm{g} \\
\text { Protein) }\end{array}$ & $\begin{array}{l}\text { Approx. Dose } \\
(\mu \mathrm{g} / \mathrm{g} \text { Insect })\end{array}$ & N Injected & $\begin{array}{c}\text { Moulted to L6 } \\
(\%)\end{array}$ & $\begin{array}{l}\text { Mean Period Spent in } \\
\text { Fifth Stadium (days) }\end{array}$ & $\begin{array}{l}\text { Mean Time to Pupa- } \\
\text { tion / Death (days) }\end{array}$ & $\begin{array}{c}\text { Supernumerary } \\
\text { Stadia (\%) }\end{array}$ & Pupated (\%) & $\begin{array}{c}\text { Deformed Pupae (\%)(N } \\
\text { Deformed / N Pupae) }\end{array}$ \\
\hline \multicolumn{9}{|l|}{ Fifth instars } \\
\hline 0.0 & 0.0 & 32 & 100.0 & $3.9 \pm 0.10$ & $11.5 \pm 0.45$ & 0.0 & 90.6 & $6.3(2 / 29)$ \\
\hline 0.05 & 0.8 & 28 & 100.0 & $4.3 \pm 0.34(\mathrm{~ns})$ & $12.1 \pm 0.34(\mathrm{~ns})$ & 0 & 100.0 & $10.7(3 / 28)$ \\
\hline 0.25 & 4.0 & 30 & 76.7 & $4.8 \pm 0.26$ (ns) & $12.1 \pm 0.56(\mathrm{~ns})$ & 20.0 & 40.0 & $41.7(5 / 12)$ \\
\hline 0.5 & 8.0 & 25 & 36.0 & $7.4 \pm 0.50(* * *)$ & $9.4 \pm 0.53(*)$ & 4.0 & 8.0 & $50.0(1 / 2)$ \\
\hline 1.0 & 16.0 & 35 & 14.3 & $8.4 \pm 0.56(* * *)$ & $9.3 \pm 0.58(*)$ & 0.0 & 2.8 & $0.0(0 / 1)$ \\
\hline 2.0 & 32.0 & 25 & 0.0 & $9.3 \pm 0.80(* * *)$ & $9.3 \pm 0.80(*)$ & 0.0 & 0.0 & $0.0(0 / 0)$ \\
\hline 0.05 & 0.3 & 10 & - & - & $6.1 \pm 0.78(\mathrm{~ns})$ & 0.0 & 80.0 & $12.5(1 / 8)$ \\
\hline 0.1 & 0.6 & 20 & - & - & $6.0 \pm 0.74(\mathrm{~ns})$ & 0.0 & 65.0 & $69.2(9 / 13)$ \\
\hline 0.25 & 1.5 & 20 & - & - & $7.9 \pm 1.25(\mathrm{~ns})$ & 20.0 & 55.0 & $45.5(5 / 11)$ \\
\hline 0.5 & 3.0 & 11 & - & - & $7.5 \pm 0.73$ (ns) & 0.0 & 9.1 & $66.6(2 / 3)$ \\
\hline 1.0 & 6.0 & 10 & - & - & $9.0 \pm 0.91(\mathrm{~ns})$ & 0.0 & 20.0 & $100.0(2 / 2)$ \\
\hline 2.0 & 12.0 & 10 & - & - & $9.2 \pm 1.21(\mathrm{~ns})$ & 0.0 & 0.0 & $0.0(0 / 0)$ \\
\hline
\end{tabular}

The developmental times of hosts were analysed by one-way ANOVA and the means of venom-injected hosts compared with the control means using Dunnet multiple comparison tests. The level of significance is indicated as $\mathrm{ns}=\mathrm{P}>0.05, * \mathrm{P}<0.05$, *** $\mathrm{P}<0.001$.

In the fifth instar hosts there was a progressive increase in the number of larvae that failed to moult as venom dose was increased although only the highest dose eliminated ecdysis (Table 1). However, successful ecdysis did not always lead to the successful completion of development (i.e. normal pupation). This fact was best illustrated by larvae injected by the $0.25 \mu \mathrm{g}$ dose where $76.7 \%$ moulted to the sixth stadium but only about $20 \%$ went on to form viable pupae, the remainder becoming moribund or producing deformed pupae. Sixth instar larvae demonstrated a similar dose response to the increasing venom doses as fifth stadium larvae with caterpillars treated with the highest dose $(2.0 \mu \mathrm{g})$ all becoming arrested prior to pupation whilst only a small proportion of insects treated with the 0.5 and $1.0 \mu \mathrm{g}$ doses formed pupae, of which most were deformed.

The formation of deformed pupae was most evident in sixth instar larvae, particularly those injected with the $0.1 \mu \mathrm{g}$ dose where nine out of the 13 pupae $(69 \%)$ produced were non-viable (Table 1). Injection of venom into fifth instar caterpillars significantly increased the period of time spent within that stadium $\left(F_{6,198}=27.27, \mathrm{P}<0.001\right)$ from $3.9 \mathrm{~d}$ in control larvae to $9.3 \mathrm{~d}$ in insects injected with $2.0 \mu \mathrm{g}$ venom protein. However, the duration of the sixth stadium, either to pupation or death, was not extended significantly in caterpillars injected at the start of that stage $\left(F_{6,63}=2.01, \mathrm{P}=0.078\right)$ (Table 1).

In the case of fifth instars, a venom dose of $\geq 0.5 \mu \mathrm{g}$ of protein resulted in the near total elimination of growth simi- lar to that seen in parasitized hosts (Fig. 2A). When the mean maximum weights that caterpillars achieved post treatment were examined, it was apparent that doses of $\geq 0.5 \mu \mathrm{g}$ had a significantly deleterious effect on their capacity to grow (one-way ANOVA, $F_{6,82}=39.21, P<0.001$ ) (Fig. 2B). However, it was notable that the maximum weights achieved by larvae injected with the 0.1 and $0.25 \mu \mathrm{g}$ venom doses did not differ significantly from the controls (Dunnet multiple comparisons, $\mathrm{P}>0.05$ ) despite the fact that both treatments reduced developmental success. Venom injection had a significant, although comparatively reduced effect, on sixth instar larval growth that was highly dependent on the dose delivered (one-way ANOVA, $F_{6,79}=3.23$, P $<0.01$ ) (Fig. 2C,D). Only the $2.0 \mu \mathrm{g}$ dose consistently reduced growth to the extent that the maximum weight achieved by treated larvae was significantly less than that for controls (Dunnet multiple comparisons, $\mathrm{P}<0.01$ ) (Fig. 2D), despite doses of 0.1 $\mu \mathrm{g}$ and above markedly affecting developmental success and causing slower rates of growth (growth curves not shown).

The injection of E. pennicornis venom had a profound effect on the survival of two factitious hosts (Table 2). When injected with a protein dose $(0.5 \mu \mathrm{g})$ that consistently resulted in developmental arrest in most L. oleracea, the majority of fifth instar $S$. littoralis similarly became developmentally arrested $(80 \%)$. This cessation in development occurred at a point just prior to when ecdysis would normally have occurred in the majority $(70 \%)$ of the treated larvae (Table 2). As a result, the maximum weight achieved by 
A
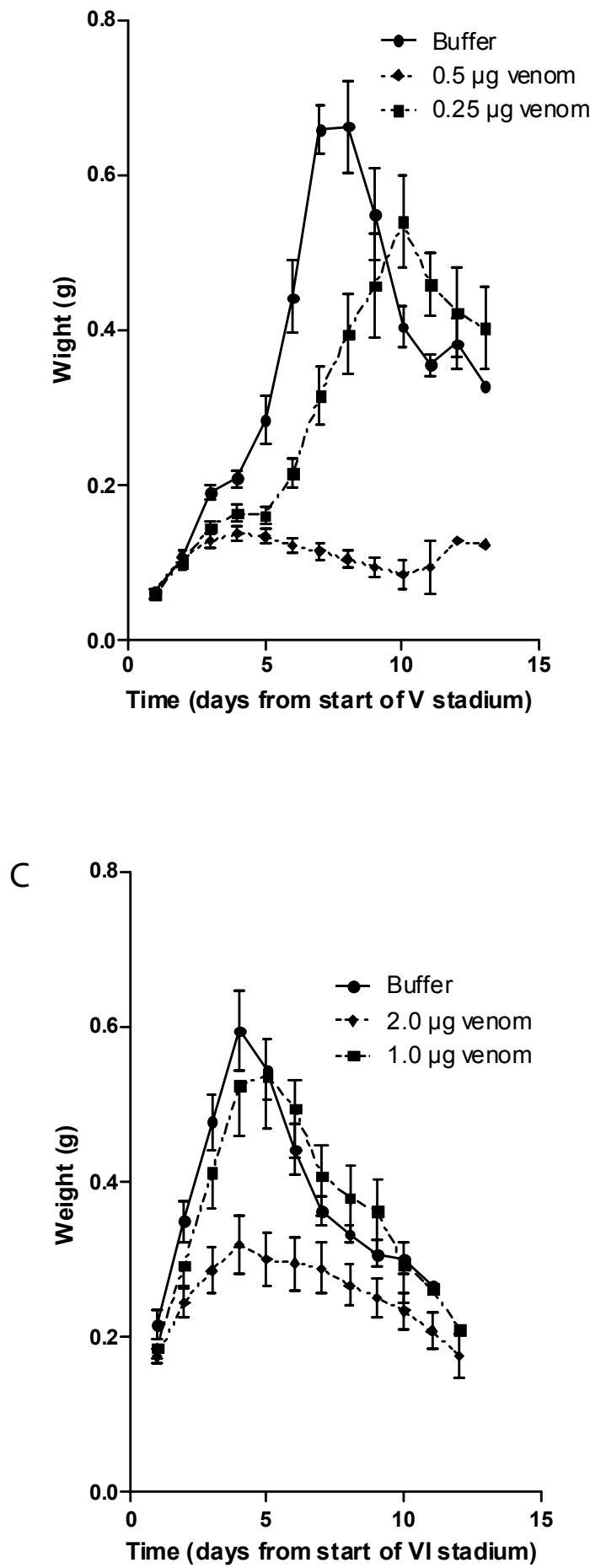

B
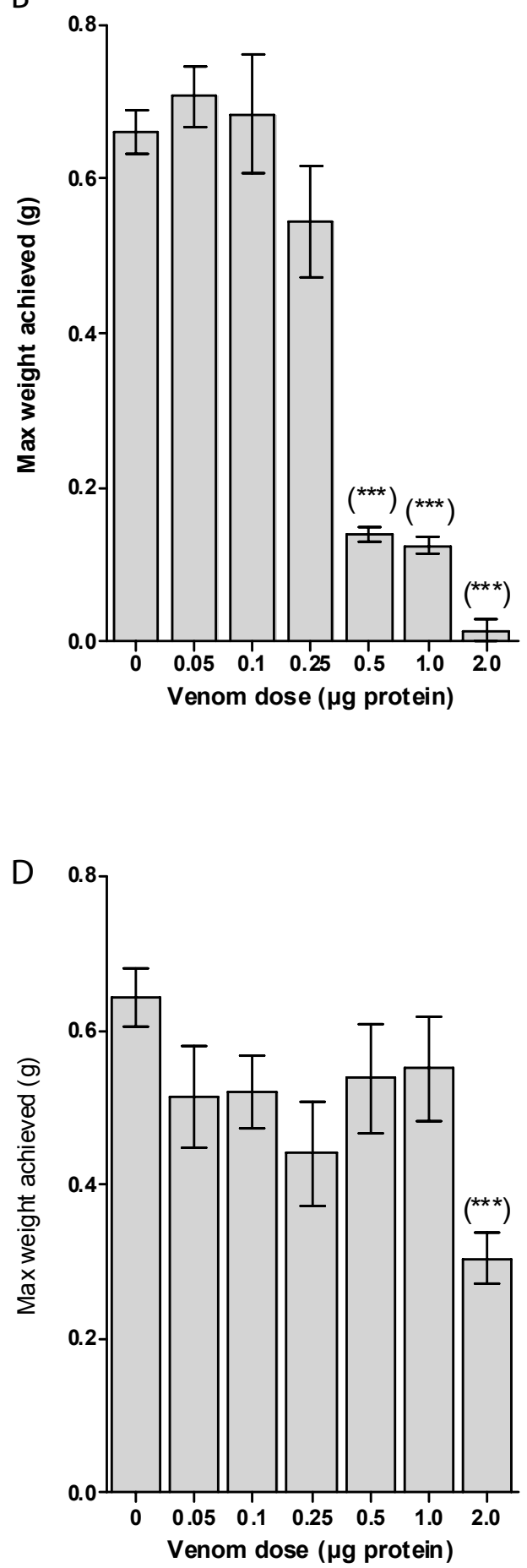

Fig. (2). The effect of E. pennicornis venom on the growth of L. oleracea larvae injected at the beginning of the fifth and sixth stadium. (A) Growth curves of fifth instar larvae at selected doses and (B) maximum weights attained for all doses. (C) The growth of sixth instar larvae at selected doses alongside (D) the maximum weights achieved by larvae for all doses.

venom-injected larvae, at $0.20 \pm 0.07 \mathrm{~g}$, was significantly less than the $0.84 \pm 0.04 \mathrm{~g}$ attained by the control insects $(\mathrm{t}=$ $7.75, \mathrm{df}=18, \mathrm{P}<0.001)$. Manduca sexta larvae injected with $5 \mu \mathrm{g}$ of venom protein at the start of the penultimate (fourth) stadium, whilst retaining the capacity to moult, all failed to pupate and became moribund during their final larval sta- dium ca. 20 days after injection (Table 2). Following ecdysis to the fifth stadium, all larvae continued to grow at a reduced rate for up to two weeks but only achieved a maximum weight of $4.46 \pm 0.94 \mathrm{~g}$, a value significantly less than the control average of $8.86 \pm 0.27 \mathrm{~g}(\mathrm{t}=5.13$, df $=18, \mathrm{P}<$ 0.001) (Fig. 3A, B). All larvae turned black at a point just 
Table 2. The Effect on the Successful Development of $S$. littoralis and $M$. sexta Larvae Following Injection with Doses of Crude Venom at the Start the Penultimate Larval Stadium

\begin{tabular}{|c|c|c|c|c|c|c|}
\hline $\begin{array}{l}\text { Venom Dose } \\
\text { ( } \mu \text { g Protein) }\end{array}$ & $\begin{array}{c}\text { Approx. Dose } \\
(\mu \mathrm{g} / \mathrm{g} \text { Insect }\end{array}$ & $\mathrm{N}$ injected & $\begin{array}{c}\text { Moulted to Final } \\
\text { Larval Stadium (\%) }\end{array}$ & $\begin{array}{l}\text { Supernumerary } \\
\text { Stadia }(\%)\end{array}$ & Pupated (\%) & $\begin{array}{l}\text { Deformed Pupae (\%) } \\
\text { (N Deformed/N Pupae) }\end{array}$ \\
\hline \multicolumn{7}{|l|}{ S. littoralis (L5) } \\
\hline 0.0 & 0.0 & 10 & 100.0 & 0.0 & 100.0 & $10.0(1 / 10)$ \\
\hline 0.5 & 8.0 & 10 & 30.0 & 0.0 & 20.0 & $0.0(0 / 2)$ \\
\hline 0.0 & 0.0 & 10 & 100.0 & 0.0 & 90.0 & $0.0(0 / 9)$ \\
\hline 5.0 & 15.0 & 10 & 100.0 & 0.0 & 0.0 & $0.0(0 / 0)$ \\
\hline
\end{tabular}

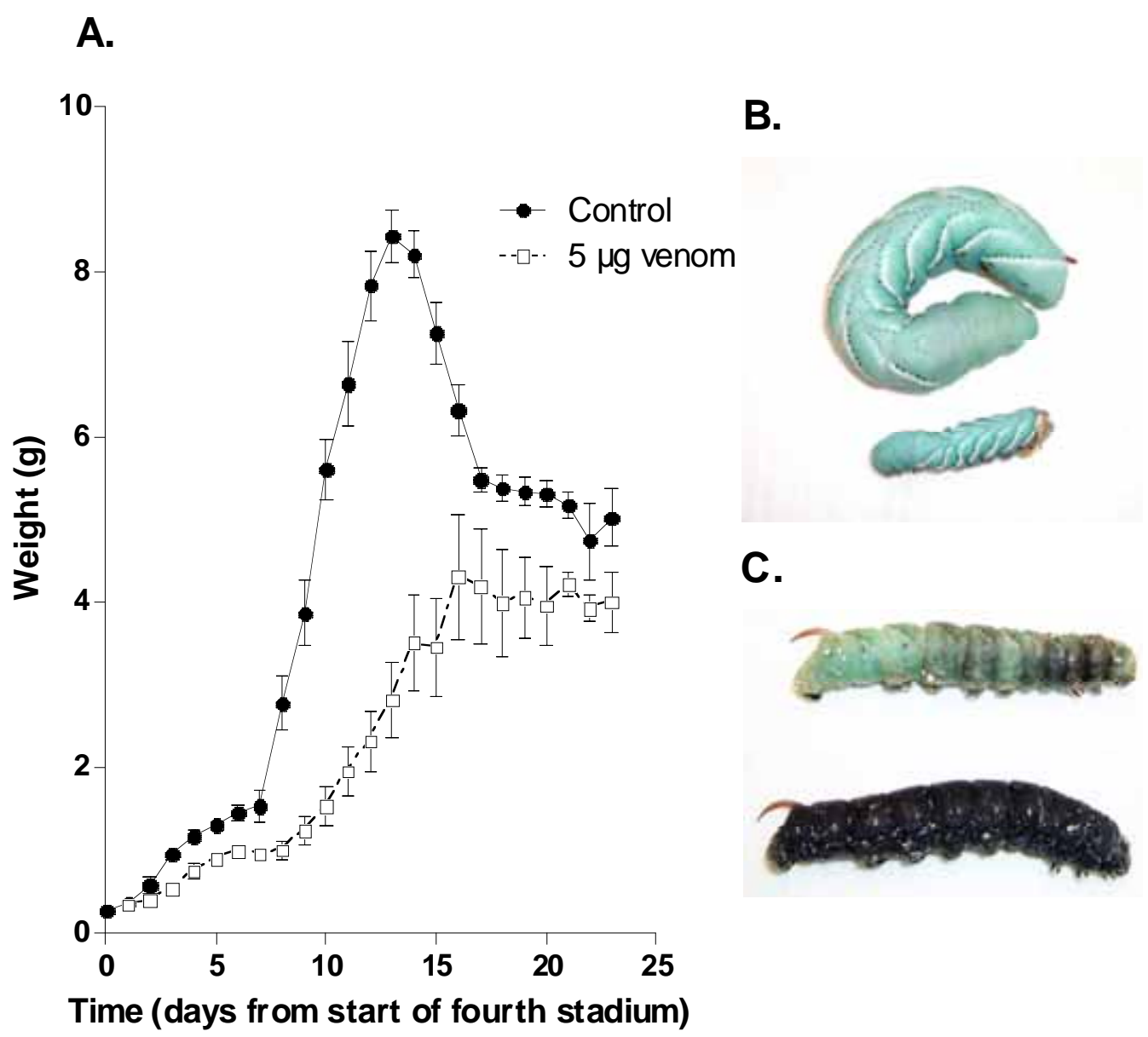

Fig. (3). (A) The effect of the injection of $5.0 \mu \mathrm{g}$ of venom into fourth instar $M$. sexta larvae. (B) The comparative sizes of control (top) and injected hosts (bottom) 13 days after treatment and (C) the melanization that occurs in treated larvae prior to death (ca. 20 days post treatment).

prior to the point when the normal onset of pupation would occur and died one or two days later (Fig. 3C).

\section{Activity of FPLC Fractions and Comparisons with the Juvenilizing Activity of Methoprene}

A preliminary screen of FPLC fractions indicated the presence of two series of fractions that contained significant activity and resulted in developmental dysfunction in injected insects (results not shown). These fractions were subjected to further investigation following concentration to approximately $40 \%$ of their initial volume. Fractions 26-33 resulted in moulting from the fifth to the sixth stadium being eliminated in some or all insects. This data indicated the presence of an anti-moulting factor (AMF) although the fact that most arrested insects died after commencing ecdysis (Fig. 4B) meant that the effect differed somewhat from naturally stung hosts where most insects do not show any attempt to moult. The injection of the most active fractions (26-30) gave largely similar levels of anti-moulting activity with the exception of fraction 30 where $50 \%$ moulted and went on to 


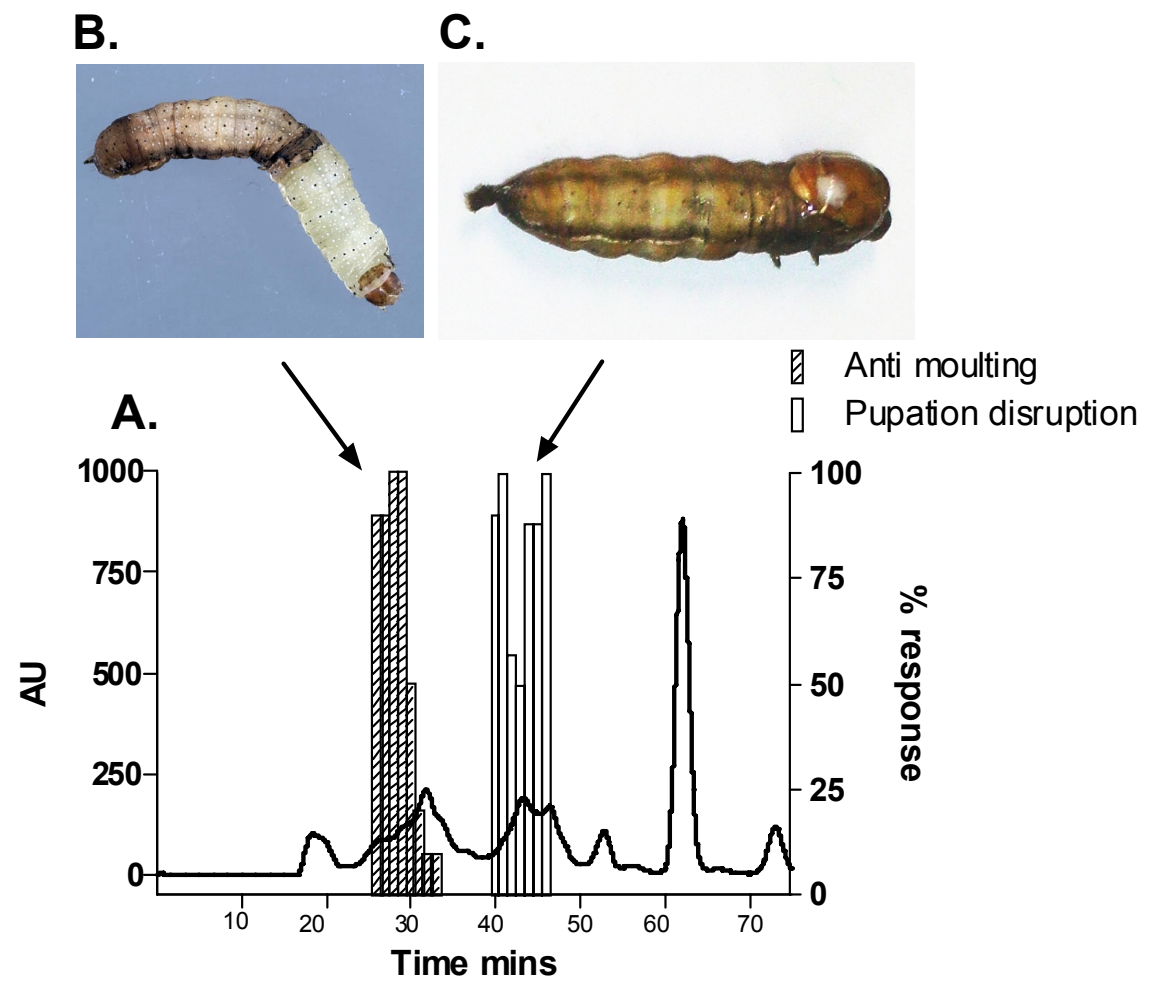

Fig. (4). (A) The elution of the anti-moulting and JH-modulating-like factors (see text for details) and the percentage of injected larvae (\% response) exhibiting the pathologies associated with (B) the anti-moulting factor (AMF) and the (C) putative JH modulating factor (pJHMF).

Table 3. The Effect of Concentrated FPLC Fractions on the Development of L. oleracea Larvae Injected at the Beginning of the Fifth Stadium and Comparisons with the Developmental Effects of Topical Applications of the JHA Methoprene to Fifth and Sixth Instar Larvae

\begin{tabular}{|c|c|c|c|c|c|}
\hline $\begin{array}{c}\text { Activity Type / Fraction } \\
\text { Number }\end{array}$ & N Treated & $\begin{array}{l}\text { Total Protein Injected } \\
\text { per Insect }(\mu \mathrm{g})\end{array}$ & $\begin{array}{c}\text { Successful L5-L6 Moult } \\
(\%)\end{array}$ & Pupation (\%) & $\begin{array}{l}\text { \% Deformed Pupae (N } \\
\text { Deformed / N Pupae) }\end{array}$ \\
\hline \multicolumn{6}{|c|}{ Moult inhibitory fractions $(A M F) L 5$} \\
\hline Buffer (PBS) & 20 & 0.0 & 90.0 & 80.0 & $6.3(1 / 16)$ \\
\hline 26 & 10 & 0.37 & 10.0 & 10.0 & $100.0(1 / 1)$ \\
\hline 28 & 10 & 0.41 & 0.0 & 0.0 & $0.0(0 / 0)$ \\
\hline 29 & 10 & 0.62 & 0.0 & 0.0 & $0.0(0 / 0)$ \\
\hline 30 & 10 & 0.48 & 90.0 & 50.0 & $100.0(5 / 5)$ \\
\hline \multicolumn{6}{|l|}{ JH-like activity ( $p J H M F)$ L5 } \\
\hline 45 & 10 & 0.09 & 100.0 & 90.0 & $88.9(8 / 9)$ \\
\hline 46 & 10 & 0.06 & 90.0 & 80.0 & $100.0(8 / 8)$ \\
\hline
\end{tabular}


(Table 3). Contd.....

\begin{tabular}{|c|c|c|c|c|c|}
\hline $\begin{array}{c}\text { Activity Type / Fraction } \\
\text { Number }\end{array}$ & N Treated & $\begin{array}{c}\text { Total Protein Injected } \\
\text { per Insect }(\mu \mathrm{g})\end{array}$ & $\begin{array}{c}\text { Successful L5-L6 Moult } \\
(\%)\end{array}$ & Pupation (\%) & $\begin{array}{c}\text { \% Deformed Pupae (N } \\
\text { Deformed / N Pupae) }\end{array}$ \\
\hline \multicolumn{6}{|l|}{ Methoprene applications L5 } \\
\hline 0.0 & 20 & - & 85.7 & 81.0 & $0.0(0 / 17)$ \\
\hline 50.0 & 20 & - & 100.0 & 90.0 & $38.9(7 / 18)$ \\
\hline \multicolumn{6}{|l|}{ Methoprene applications L6 } \\
\hline 0.0 & 20 & - & - & 100.0 & $5.0(1 / 20)$ \\
\hline 50.0 & 20 & - & - & 60.0 & $90.9(10 / 11)$ \\
\hline 100.0 & 20 & - & - & 20.0 & $100.0(4 / 4)$ \\
\hline
\end{tabular}

form deformed pupae (Table 3). Fraction 27 was seen to be the most active with a protein dose of $0.33 \mu \mathrm{g}$ completely eliminating ecdysis. However, whilst almost all other fractions allowed for the completely normal development of $>85 \%$ of injected caterpillars (results not shown), the formation of viable pupae was markedly inhibited by a small number of samples (fractions 40-46). In these fractions the majority of injected larvae moulted normally to the sixth instar, continued to feed, and developed normally up to the point of pupation whereupon they either failed to pupate or formed a non-viable deformed pupa (Fig. 4C). In the case of fraction $43,60 \%$ of those initially injected produced deformed pupae whilst the remainder died just prior to pupation, often at the point where head capsule slippage had occurred. In most cases, pupation (attempted or complete) of insects injected with fractions 43-46 took place 2-3 days after the control insects (data not shown). Activity of this type closely resembled exogenous juvenile hormone $(\mathrm{JH})$ treatment and these fractions were considered as potentially containing a factor that affects $\mathrm{JH}$ levels (putative $\mathrm{JH}$ modulating factor, pJHMF).

The growth of insects injected with the AMF fractions closely resembled that of insects injected with whole venom (Fig. 5A) such that of larvae at the start of both the fifth and sixth stadium showed markedly reduced growth followed by developmental arrest. The juvenilizing effects of the pJHMF fractions were compared with topical applications of the JHA methoprene. Injection of the pJHMF (using a pooled sample of fractions 40-46) allowed for the continued growth of most larvae for several days longer than that of control insects (Fig. 5A) followed by the formation of deformed pupae. This effect closely resembled that of the topical application of $100 \mu \mathrm{g}$ methoprene, particularly when the JHA was applied at the start of the sixth stadium (Fig. 5B) where growth rate was initially similar to the control insects. The effect of application of methoprene at the start of the fifth
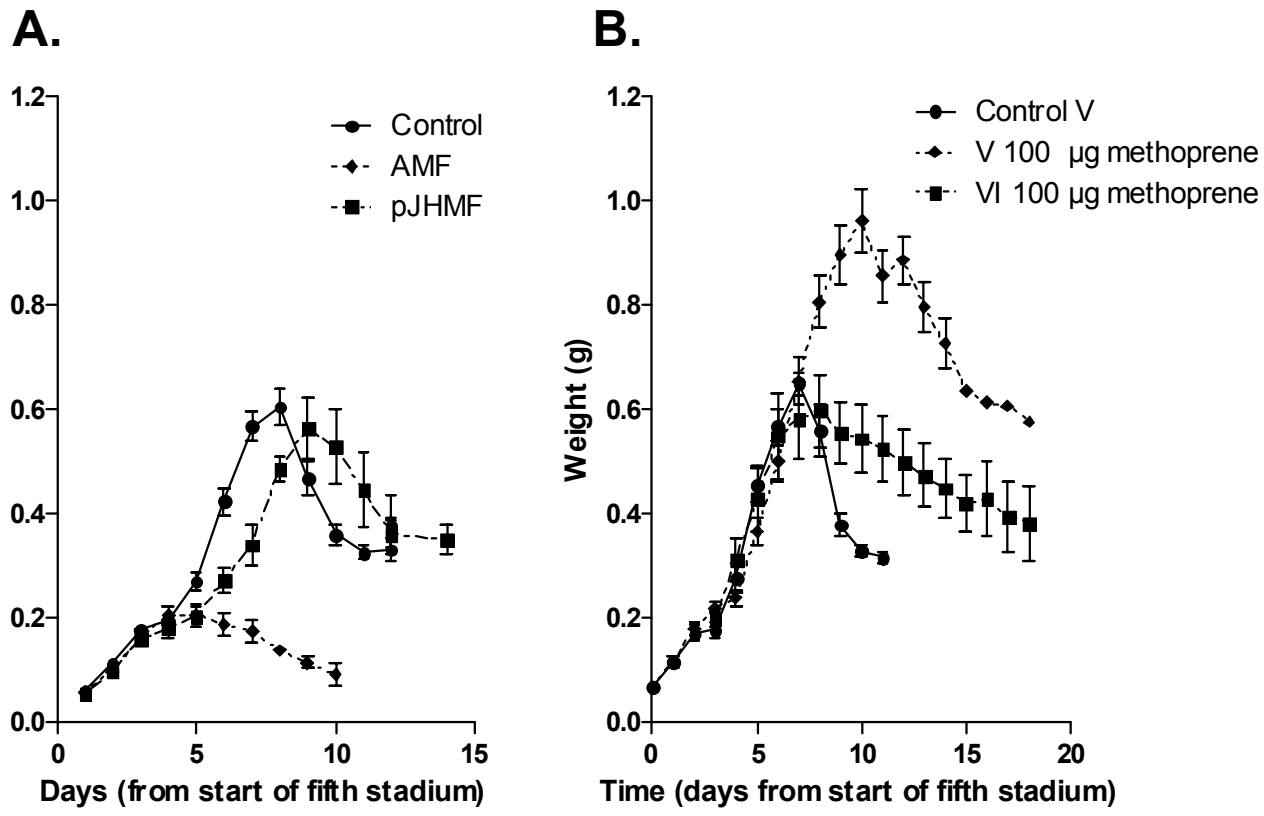

Fig. (5). The effect on growth of the AMF and pJHMF factors when injected into fifth instar L. oleracea larvae (A) and the growth of caterpillars when topically treated with $100 \mu \mathrm{g}$ of methoprene at the start of either the fifth or sixth stadium (B). 
stadium, however, was less similar with insects growing much larger during a significantly extended sixth stadium of approximately $14 \mathrm{~d}$ (control duration ca. $7 \mathrm{~d})(\mathrm{t}=11.19$, $\mathrm{df}=$ $36, \mathrm{P}<0.001)$. Despite this considerable extension of the final larval stadium, and the larvae attaining much larger weights, $85 \%$ of fifth instar larvae treated with methoprene were able to form pupae (viable and non viable) as opposed to $20 \%$ in sixth stadium larvae treated with the equivalent JHA dose.

\section{DISCUSSION}

The crude venom of E. pennicornis is highly active and induces developmental arrest at relatively low levels of injected protein. The pathology observed is similar to that previously reported $[10,15,16]$ with insects ceasing to feed $2-4 \mathrm{~d}$ after injection, becoming moribund and failing to moult to the next larval stadium. The injection of doses of venom at levels below those that reliably prevent ecdysis revealed that prevention of successful pupation frequently occurs even if the last larval-larval moult is not prevented. A range of other developmental abnormalities, such as the occurrence of supernumerary stadia and incomplete ecdysis, also occur at low venom doses, pathologies that were not reported in earlier work on the activity of the venom of this wasp. The induction of supernumerary stadia, in particular, is indicative of the $\mathrm{JH}$ manipulation that is known to occur in parasitized hosts [4], a phenomenon that is usually masked by the antimoulting activity of the venom. However, the marked growth reduction that is characteristic of natural envenomation was only associated with the AMF in injected $L$. oleracea and insects injected with the pJHMF grow more or less normally. Notably, in terms of the venom dose per unit fresh weight required to prevent the successful completion of larval development, sixth stadium larvae appear much more susceptible to the developmental perturbations induced by the venom than the much smaller fifth instar larvae.

Whilst the two distinct biological effects could be construed as being brought about by the diminishing effects of a single factor, the fractionation of venom by FPLC effectively separated the two types on activity, producing fractions that predominantly, though not exclusively, gave either antimoulting or JH-like activity. The first phenomenon, which has been widely reported as an effect of E. pennicornis's venom, is crucial to the survival of larvae developing on fifth (penultimate instar) hosts that would be shed with the cast cuticle upon ecdysis. The second effect has not been reported upon previously and may be caused by the factor responsible of the increased levels of juvenile hormone that are observed in hosts parasitized at the start of the final larval stadium [4]. The malformed pupae observed following the injection of certain fractions are highly reminiscent of larvae that have been exposed to abnormally high levels of $\mathrm{JH}$ during their final instar, a time when $\mathrm{JH}$ is virtually absent in larval Lepidoptera [12,21]. It is, therefore, likely that this second biological activity results from a JH-modulating factor that targets either JH biosynthesis or its metabolism by juvenile hormone esterase, both effects that have been recorded from L. oleracea parasitized by E. pennicornis [4] and a number of other parasitoid-host associations $[6,22]$. The current work also indicates that the JH-like activity would appear to only come into effect in final (sixth) instar larvae, even when caterpillars are injected (or envenomated) in the preceding sta- dium. This supposition is substantiated by the fact that topical applications of methoprene onto fifth stadium larvae produced much more marked effects on growth that when it is applied to sixth instar caterpillars, where the observed effects very closely resembled injection of the pJHMF into penultimate instar larvae that subsequently go on to moult to this stadium. Such observations provide further evidence to substantiate the fact that E. pennicornis, and other parasitoids, use maternally-derived parasitoid factors to manipulate different host stages in different ways [4,8, 23,24].

Whilst good separations of biological activity were achieved by gel-filtration, the fractions remained complex and, following additional concentration, in excess of 20 protein bands were still present in the AMF samples and ca. 5 in the pJHMF fractions when separated by polyacrylamide gel electrophoresis and stained with Coomassie blue (results not shown). Work is ongoing to purify the venom fractions further so that accurate characterization and partial sequencing of the physiologically active factors present in E. pennicornis venom can be achieved. Furthermore, measurements of $20 \mathrm{E}$ and $\mathrm{JH}$ following injection of the AMF and pJHMF are strongly indicated to confirm the biological inferences that are made here.

The current findings provide further evidence for the dual endocrine regulation strategy employed by E. pennicornis that has been alluded to previously, and provides a correlation between existing endocrinological measurements and biological observations [4]. In whole venom, the antimoulting activity masks other underlying activities of which, as is shown here, includes a factor(s) that induces JH-like effects and probably operates at comparatively lower concentrations than the AMF. It was noted, however, that some fractions containing the AMF also induce some deformity in pupae that derive from hosts that were not prevented from moulting, an observation that requires further study to determine if the deformity differs qualitatively from that induced by the pJHMF. It is also important to note that the anti-ecdysis activity of the AMF fractions did not exactly reflect that seen in naturally envenomated hosts, or those injected with whole venom, in that partial ecdysis almost always occurs. This could be construed as a response to a sub-optimal dose of the AMF or, potentially, could be due to the fact that more than one factor is responsible for the complete elimination of all moulting activity.

Previous work $[8,14]$ has shown that early sixth stadium hosts ( 0 - $48 \mathrm{~h}$ post ecdysis) are preferentially parasitized by E. pennicornis and suggest that juvenilization, and the capacity to induce it, have been selective drivers in this parasitoid preferentially parasitizing hosts of this age. The powerful juvenilizing effect that a component of E. pennicornis's venom induces in the host lends credence to the fact that it is probably critical for the wasp to ensure that hosts do not become physiologically committed to pupation once they have been parasitized. This need is likely to be necessitated by the specific nutritional needs of the parasitoid's larva, requirements that are not met by insects that are physiologically committed to the production of pupal tissues through the absence of $\mathrm{JH}$ that typically occurs during the ultimate larval instar of L. oleracea and other lepidopterous larvae. As JH manipulation to prevent pupal commitment is only required for the regulation of sixth instar larvae, it is therefore likely 
that E. pennicornis has developed strategies for the manipulation of hosts that only come into effect when hosts enter this stadium.

It was also interesting to observe that whilst whole venom induces effects in the closely related factitious host $S$. littoralis indistinguishable to those seen in L. oleracea, in that moulting is severely disrupted, only the JH-like effects manifest themselves in the more distantly related $M$. sexta at a comparable weight-for-weigh dose. However, it was noted that growth is markedly reduced in $M$. sexta injected with whole venom, despite the fact they are unaffected by the anti-moulting factor contained within it. This contrasts with findings from $L$. oleracea where growth modulation is always associated with anti-moulting activity. Although the activity of some parasitoid venoms have been shown to operate well beyond their natural host range [25], the partition of activity observed in $M$. sexta is extremely interesting and may provide a very useful tool for the further study of the biologically active components of E. pennicornis's venom at the physiological and biological level.

Much recent work into the host regulatory effects of parasitoid venoms has been driven by the need to find biologically active compounds that may be used as novel insecticides [26]. In the case of E. pennicornis, at least two distinct anti-insect factors are detected within the venom with biological activities that have the potential to be highly specific to lepidopteran larvae. Work is currently ongoing to further characterize these and other factors present within the venom of this parasitoid with a view to exploiting their antiinsect potential in the future.

\section{ACKNOWLEDGEMENT}

This work was, in part, supported by a Defra-funded LINK project in collaboration with Isagro Riserca to whom the authors are grateful.

\section{REFERENCES}

[1] Vinson SB, Iwantsch GF. Host regulation in insect parasitoids. Q Rev Biol 1980; 55: 43-465.

[2] Beckage NE. Modulation of immune responses to parasitoids by polydnaviruses. Parasitology 1998; 116: S57-S64.

[3] Bell HA, Kirkbride-Smith AE, Marris GC, Edwards JP. Teratocytes of the solitary endoparasitoid Meteorus gyrator (Hymenoptera : Braconidae): morphology, numbers and possible functions. Physiol Entomol 2004; 29: 335-43.

[4] Edwards JP, Bell HA, Audsley N, et al. The ectoparasitic wasp Eulophus pennicornis (Hymenoptera: Eulophidae) uses instarspecific endocrine disruption strategies to suppress the development of its host Lacanobia oleracea (Lepidoptera: Noctuidae). J Insect Physiol 2006; 52: 1153-62.

[5] Cole TJ, Beckage NE, Tan FF, Srinivasan A, Ramaswamy SB. Parasitoid-host endocrine relations: self-reliance or co-optation? Insect Biochem Mol Biol 2002; 32: 1673-9.

[6] Schafellner C, Marktl RC, Nussbaumer C, Schopf A. Parasitisminduced effects of Glyptapanteles liparidis (Hym., Braconidae) on the juvenile hormone titer of its host, Lymantria dispar: the role of the parasitoid larvae. J Insect Physiol 2004; 50: 1181-9.

[7] Dover BA, Menon A, Brown RC, Strand MR. Suppression of juvenile hormone esterase in Heliothis virescens by Microplitis demolitor calyx fluid. J Insect Physiol 1995; 41: 809-17.
[8] Bell HA, Weaver RJ. Ability to host regulate determines host choice and reproductive success in the gregarious ectoparasitoid Eulophus pennicornis (Hymenoptera : Eulophidae). Physiol Entomol 2008; 33: 62-72.

[9] Pennacchio F, Strand MR. Evolution of developmental strategies in parasitic Hymenoptera. Annu Rev Entomol 2006; 51: 233-58.

[10] Weaver RJ, Marris, GC, Olieff S, Mosson JH, Edwards JP. Role of ectoparasitoid venom in the regulation of haemolymph ecdysteroid titres in a host noctuid moth. Arch Insect Biochem Physiol 1997; 35: 169-78.

[11] Weaver RJ, Marris GC, Bell HA, Edwards JP. Identity and mode of action of the host endocrine disrupters from the venom of parasitoid wasps. In: Edwards JP, Weaver RJ, Eds., Endocrine interactions of insect parasites and pathogens. Oxford: Bios 2001; pp. 3358 .

[12] Nijhout HF. Insect Hormones USA: Princeton University Press 1999.

[13] Coudron TA, Kelly TJ, Puttler B. Developmental responses of Trichoplusia ni (Lepidoptera, Noctuidae) to parasitism by the ectoparasite Euplectrus plathypenae (Hymenoptera, Eulophidae). Arch Insect Biochem Physiol 1990; 13: 83-94.

[14] Bell HA, Marris GC, Prickett AJ, Edwards JP. Influence of host size on the clutch size and developmental success of the gregarious ectoparasitoid Eulophus pennicornis (Nees) (Hymenoptera : Braconidae) attacking larvae of the tomato moth Lacanobia oleracea (L.) (Lepidoptera : Noctuidae). J Exp Biol 2005; 208: 3199-209.

[15] Marris GC, Weaver RJ, Bell J, Edwards JP. Venom from the ectoparasitoid wasp Eulophus pennicornis disrupts host ecdysteroid production by regulating host prothoracic gland activity. Physiol Entomol 2001; 26: 229-38.

[16] Marris GC, Edwards JP. The biology of the ectoparasitoid wasp Eulophus pennicornis (Hymenoptera: Eulophidae) on host larvae of the tomato moth, Lacanobia oleracea (Lepidoptera: Noctuidae). Bull Entomol Res 1995; 85: 507-13.

[17] Poitout S, Bues R. Elevage de plusieurs espèces de lépidoptères Noctuidae sur milieu artificiel riche et sur milieu artificiel simplifié. Ann Zool Ecol Anim 1970; 2: 79-91.

[18] Corbitt TS, Bryning G, Olieff S, Edwards JP. Reproductive, developmental and nutritional biology of the tomato moth, Lacanobia oleracea (Lepidoptera: Noctuidae) reared on artificial diet. Bull Entomol Res 1996; 86: 647-57.

[19] Yamamoto R. Mass rearing of the tobacco hornworm. II. Larval rearing and pupation. J Econ Entomol 1969; 62: 1427-31.

[20] Bradford MM. A rapid and sensitive method for the quantitation of microgram quantities of protein using the principle of protein-dyebinding. Anal Biochem 1976; 72: 248-54.

[21] Edwards JP, Corbitt TC, McArdle HF, Short JE, Weaver RJ. Endogenous levels of insect juvenile hormones in larval, pupal and adult stages of the tomato moth, Lacanobia oleracea. J Insect Physiol 1995; 41: 641-651.

[22] Schafellner C, Marktl RC, Schopf A. Inhibition of juvenile hormone esterase activity in Lymantria dispar (Lepidoptera, Lymantriidae) larvae parasitized by Glyptapanteles liparidis (Hymenoptera, Braconidae). J Insect Physiol 2007; 53: 858-68.

[23] Gelman DB, Kelly TJ, Coudron TA. Mode of action of the venom of the ectoparasitic wasp, Euplectrus comstockii, in causing developmental arrest in the European corn borer, Ostrinia nubilalis. Invert Neurosci 1997; 3: 231-238.

[24] Knopp-Wright M, Coudron TA, Brandt SL. Ecological and physiological relevance of biochemical changes in a host as a result of parasitism by Euplectrus spp: a case study. In: Edwards, JP, Weaver RJ, Eds., Endocrine interactions of insect parasites and pathogens. Oxford: Bios 2001; pp. 153-76.

[25] Richards EH, De Marzo D, Port GR, Dani MP, Walters KF. Effects of the nematode Phasmarhabditis hermaphrodita and of venom from the endoparasitic wasp Pimpla hypochondriaca on survival and food consumption of the pest slug Deroceras reticulatum; implications for novel biocontrol strategies. Pest Manag Sci 2008; 64: 711-9.

[26] Beckage NE, Gelman DB. Wasp parasitoid disruption of host development: Implications for new biologically based strategies for insect control. Annu Rev Entomol 2004; 49: 299-330.

(c) Crown Copy Right; Licensee Bentham Open.

This is an open access article licensed under the terms of the Creative Commons Attribution Non-Commercial License (http://creativecommons.org/licenses/by-nc/3.0/) which permits unrestricted, non-commercial use, distribution and reproduction in any medium, provided the work is properly cited. 